\title{
Bivalve shells: ultra high-resolution paleoclimate archives
}

Bernd R. Schöne ${ }^{1}$ and Donna Surge ${ }^{2}$

Shells of bivalve mollusks provide time-constrained, multi-proxy records of climate change in any aquatic setting with unprecedented temporal resolution ranging from years to individual days. We explain why this archive is unique and list current research foci.

Climate proxy-data are crucial to better understand natural environmental variability prior to the instrumental era (Jones et al. 2001) In particular, there is a need for more sub-seasonal to annual resolutions of well-constrained and quantifiable proxy data from environmental settings for which only limited data are available, e.g. in coastal marine regions and mid- to high-latitude oceans (Solomon et al. 2007). Sclerochronology describes the investigation of the growth patterns and geochemical properties of the skeletal hard parts of bivalve shells. During the last decade, many sclerochronological studies (e.g. Schöne and Gillikin 2013) have confirmed that bivalve shells can record climate at sub-seasonal time scales (Butler et al. 2013; Schöne et al. 2003; Wanamaker et al. 2012).

\section{Bivalve shells as paleoclimate archives}

Bivalve shells can provide a precise chronology because calcium carbonate is periodically accreted to all growing shell margins (Barker 1964; Clark 1974; Jones 1980; Schöne and Surge 2012; Fig. 1). Regularly changing rates of skeletal formation are controlled and maintained by so-called biological clocks, which are constantly reset by environmental pacemakers (light, tides, food availability, etc.; Kim et al. 2003; Williams and Pilditch 1997). These internal time-keeping mechanisms ensure that the shell growth pattern is divided into time slices of approximately equal duration (Dunca and Mutvei 2001; Witbaard et al. 1997), which produce growth increments and growth lines. Growth increments represent periods of fast growth and growth lines periods of slow growth. Together, they are prerequisite for sclerochronological analyses because they can be used to measure time, and place each shell portion into a precise temporal context. Periodic growth patterns in bivalves include annual cycles (Jones and Quitmyer 1996; Pulteney 1781; Weymouth 1922), fortnightly cycles (15 and 13.5 lunar days; Evans 1972; House and Farrow 1968; Ohno 1989), as well as circadian (ca. 24 hours; Schwartzmann et al. 2011), circalunidian (lunar-daily, ca. 24.8 hours; Richardson 1987), circatidal (semidiurnal, ca. 12.4 hours, ebb/neap tide cycle; Beentjes and Williams
1986) and ultradian cycles (periods of minutes to hours; Rodland et al. 2006). This makes shells unrivaled archives for measuring time in the geological past at high resolution.

Bivalve shells also function as faithful and sensitive recorders of environmental change (Fig. 2). Like other cold-blooded animals, bivalve growth is largely controlled by external energy input in the form of temperature, and food quantity and quality. As a result, relative changes in shell growth, expressed through varying increment widths, can provide information on changes in these environmental variables (Kennish and Olsson 1975). Furthermore, the ambient physicochemical conditions (salinity, water quality and temperature, food availability, etc.) that prevailed during its growth are also preserved in the shell as geochemical and crystallographic properties. For example, shell oxygen isotope ratios $\left(\delta^{18} \mathrm{O}_{\text {shell }}\right)$ provide an ideal means to estimate past water temperature and salinity because almost all bivalve species form their shells very close to

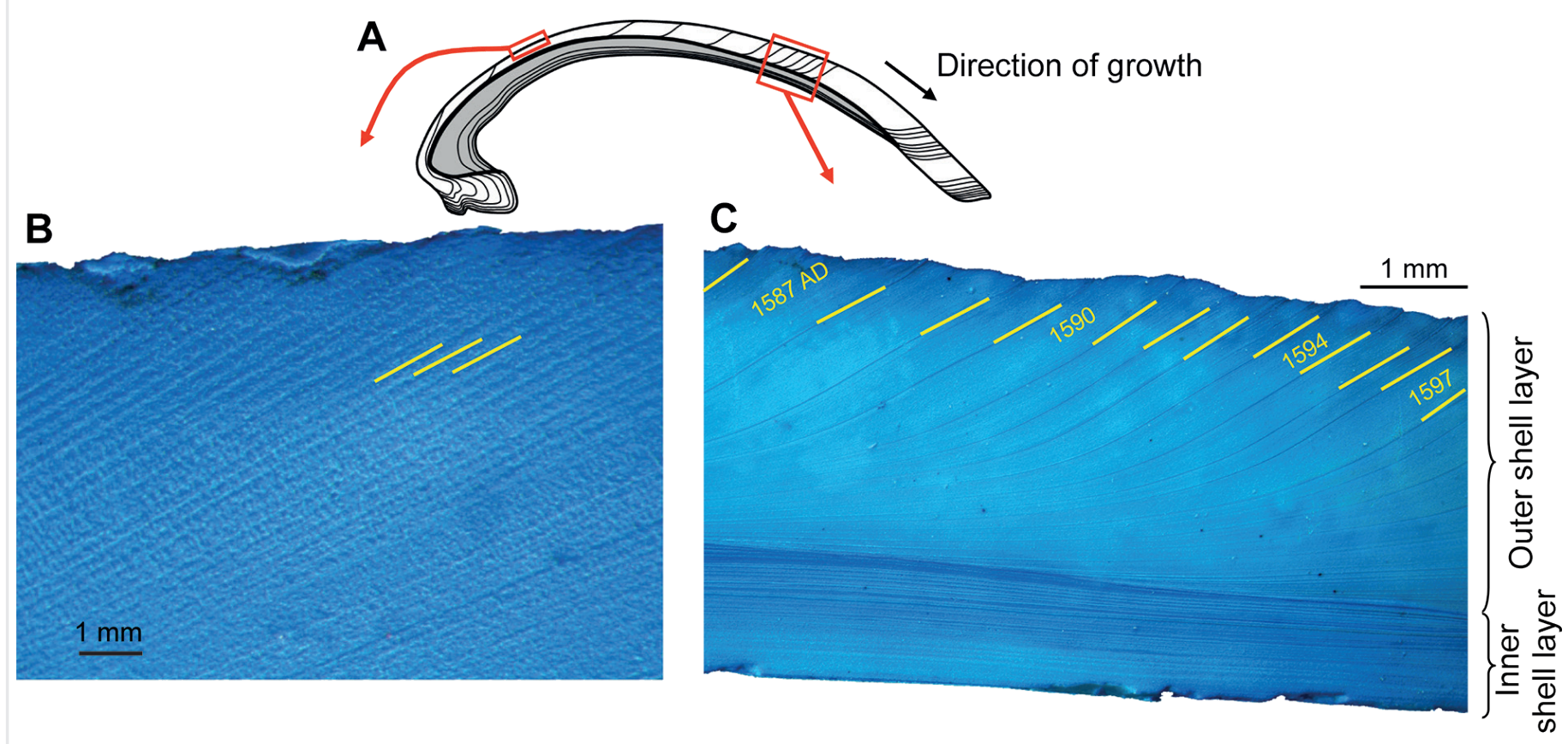

Figure 1: Growth patterns in bivalve shells (example: Arctica islandica). (A) Schematic cross-section showing internal growth patterns in the outer (white) and inner (gray) shell layers. Polished sections stained with Mutvei's solution show daily (B) and annual (C) growth patterns in the outer shell layer. Growth lines (marked yellow in B and C) delimit growth increments. 
oxygen isotopic equilibrium with the ambient environment (Epstein et al. 1953; Wefer and Berger 1991).

Whereas the life of some bivalves such as Donax variabilis ends only after a few months (Jones et al. 2005), some species of the class Bivalvia are extremely long-lived (Schöne et al. 2005; Thomson et al. 1980; Zolotarev 1980), and lead the list of the longest-lived solitary (non-colonial) animals. For example, the Pacific geoduck (Panopea generosa) reaches a lifespan of 160 years (Strom et al. 2005), the European freshwater pearl mussel (Margaritifera margaritifera) can live for well over 200 years (Mutvei and Westermark 2001), and lifespans exceeding 500 years have been reported from the deep-sea oyster Neopycnodonte zibrowii (Wisshak et al. 2009) and the ocean quahog, Arctica islandica (Butler et al. 2013). Thus, individual fossil shells open multi-century windows into past climate and provide details on paleoseasonality as well as quasi- and multi-decadal climate variability. However, such analyses are not limited to climatic snapshots. Since contemporaneous specimens from the same habitat exhibit a common response to changing environmental conditions, growth increment width-chronologies of specimens with overlapping lifespans can be combined by wiggle-matching (cross-dating) to form composite chronologies covering centuries to millennia (Butler et al. 2013; Jones et al. 1989; Lohmann and Schöne 2013; Marchitto et al. 2000; Witbaard et al. 1997; Fig. 2). With just one calendar date (e.g. the date of death of live-collected specimens), each sample can be aligned to reveal a complete chronology.

Bivalves exhibit an impressively broad and unrivaled biogeographic distribution. They have adapted to a wide range of different aquatic habitats. Today, bivalves occur in the tropics and near the poles, in shallow waters and in the deep sea, and inhabit the whole range from hypersaline to freshwater settings. Furthermore, bivalves occur abundantly in the fossil record. In fact, their evolutionary history started early in the Cambrian, i.e. $500 \mathrm{Ma}$ ago. Since humans settled along the coasts tens of thousands years ago and exploited shallow marine resources, a vast number of bivalve shells are also preserved in archeological shell middens, i.e. ancient domestic waste deposits. To date, this material has largely been used to infer human subsistence practices by reconstructing the season of collection of the bivalves (Andrus 2011; Burchell et al. 2013).

\section{Current research foci}

Growing interest in bivalve sclerochronology over the last decade has fuelled a soaring number of publications and research projects and four main research directions: (1) construction of millennial-scale master chronologies; (2) paleoclimate snapshot analysis (climate reconstruction from single specimens); (3) identification of chemical disequilibrium effects and quantification of vital and possible kinetic effects in order to optimize existing and develop new climate proxies; and (4) season-of-collection studies in archeology and anthropology. Recently, a large collaborative research initiative was funded by the EU (ARAMACC. com), whose goals include: (1) construction
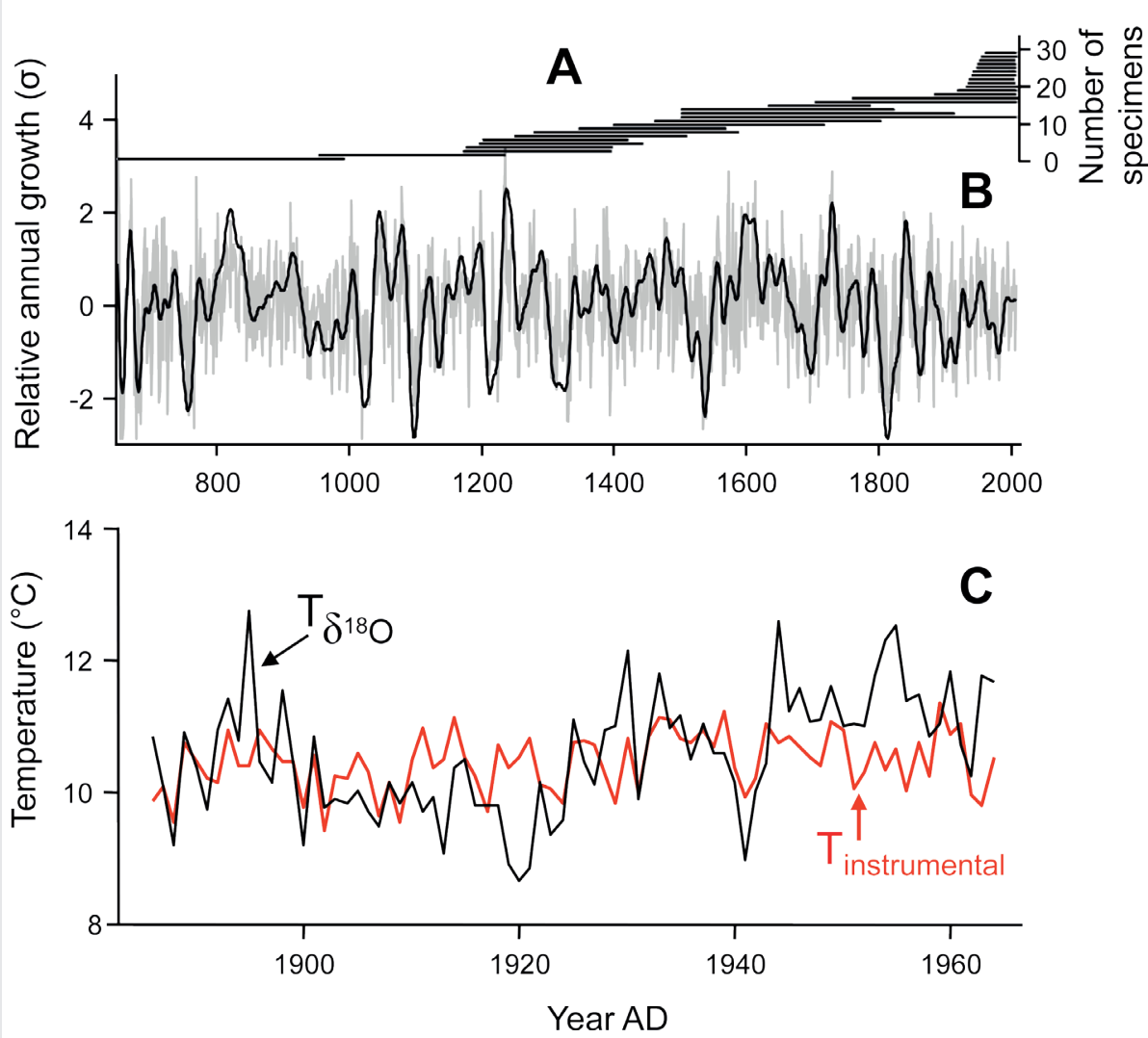

Figure 2: A 1357-year master chronology of Arctica islandica from the North Icelandic shelf (data from Butler et al. 2013). (A) Sample depth. Each horizontal line indicates the lifespan of one specimen. (B) Stacked record of growth increment width-chronologies of the 30 specimens shown in (A). The black line represents the 30-year low-pass filtered annual growth data (gray). (C) Growth increment data can be combined with highresolution geochemical analysis. The example from Schöne and Fiebig (2009) illustrates the annual temperature evolution in the southern North Sea during the late $19^{\text {th }}$ and the $20^{\text {th }}$ century reconstructed from $\delta{ }^{18} \mathrm{O}_{\text {shell }}$ values. Instrumental sea surface temperatures are given for comparison.

of millennial-scale Arctica islandica master chronologies from different settings in the boreal North Atlantic to produce paleoclimate reconstructions using stable isotopes $\left(\delta^{18} \mathrm{O}_{\text {shell' }}\right.$ $\left.\delta^{13} \mathrm{C}_{\text {shell }}\right), \mathrm{Sr} / \mathrm{Ca}$ ratios and growth-increment widths; and (2) development of novel bivalve shell-based paleoclimate proxies on the basis of microstructures (overall fabrics, shell architectures), or trace and minor elements. This will require stronger cross-disciplinary collaboration with biochemists to better understand the mechanisms of biomineralization in bivalves, in particular the complex pathways and fractionation processes involved in the transport of elements from the ambient environment to the site of calcified tissue formation (Marin et al. 2012).

\section{The future of bivalve sclerochronology}

The potential of bivalve sclerochronology in the fields of archeology and anthropology, evolution, retrospective environmental monitoring, and ecology is still waiting to be fully exploited; however, it will likely have a significant impact on paleoclimate and paleoenvironmental studies. Linking different high-resolution paleoclimate archives advances our knowledge of coupled climate systems, which will further improve predictive numerical climate models. The ubiquitous occurrence of bivalves in shallow-marine settings, especially longer-lived species, makes them suitable candidates for the construction of long master chronologies in both hemispheres. This would, for example, permit deeper analyses of cross-hemispheric climate dynamics in the future.

\section{AFFILIATIONS}

'Institute of Geosciences, University of Mainz, Germany ${ }^{2}$ Department of Geological Sciences, University of North Carolina, Chapel Hill, USA

CONTACT

Bernd R. Schöne: schoeneb@uni-mainz.de

\section{SELECTED REFERENCES}

Full reference list under:

http://www.pages-igbp.org/products/newsletters/ ref2014_1.pdf

Butler PG et al. (2013) Palaeogeog Palaeoclimatol Palaeoecol 373: 141-151

Jones DS (1980) Paleobiology 6: 331-340

Schöne BR, Gillikin DP (2013) Palaeogeog Palaeoclimatol Palaeoecol 373: 1-5

Schöne BR, Surge DM (2012) In: Selden PA (Ed) Treatise of Invertebrate Paleontology, Part N (Mollusca, Bivalvia), Treatise Online 46, 1-24

Wanamaker AD et al. (2012) Nat Commun 3, doi: 10.1038 ncomms 1901 